CIENCIA Y SOCIEDAD

Volúmen XX, Números 1 y 2

Enero-Marzo 1995

Abril-Junio 1995

\title{
LA REFORMA FINANCIERA Y MONETARIA
}

Manuel Cocco*

Hasta la década de 1960 el país contaba con un débil y pequeño mercado financiero. Durante ese período comienza a surgir el marco legal y la estructura institucional con que se inicia la expansión, diversificación y segmentación del mercado, creándose algunos bancos comerciales, el sistema de ahorros y préstamos para la vivienda y la banca de desarrollo. La banca hipotecaria surge en la década de los años 70 , pero el gran crecimiento del sector financiero tiene lugar en las décadas de 1970 y 1980.

La legislación de entonces condujo a la proliferación de los intermediarios financieros y a la creación de un sistema especializado que se diferenciaba por las condiciones y fuentes de financiamiento, por la facultad de otorgar préstamos, por la presencia de un encaje legal diferenciado, por el establecimiento administrativo de las tasas de interés,

*Economista y consultor de Ecocaribe. ex-secretario de Estado de Finanzas. 
por las a signaciones de crédito sectorial y por el otorgamiento discriminado de los incentivos fiscales.

La expansión del número de in stituciones financieras no fué el resultado de un mayor nivel de competencia, sino más bien el efecto de regulaciones que tendían a inducir la segmentación de los mercados, que estimularon el surgimiento de intermediarios financieros orientados a garantizarse el acceso a recursos abundantes y baratos del Banco Central.

Ahora bien, el mayor crecimiento del sector financiero tuvo lugar en el decenio de 1980 , cuando su participación en el PIB alcanzó 5.8\%; dicho crecimiento se produjo en el marco de un período de notable inestabilidad macroeconómica, de segmentación y represión financiera acompañado de una gran debilidad y relajamiento de los organismos responsables de la supervisión bancaria.

Es innegable que las desestabilizaciones macroeconómicas por las que ha atravesado el país, la represión financiera que estuvo presente en determinados momentos, la deficiencia en el manejo de la supervisión bancaria y de los riesgos crediticios, la ausencia de niveles de reservas adecuadas y el manejo imprudente e irresponsable de ciertos intermediarios fin ancieros en la administración de recursos ajenos, condujo a situaciones de crisis financiera. Todo lo anterior ocasionó la desaparición de un número importante de instituciones y por ende a la apropiación de una parte considerable del ahorro privado.

A partir de 1991, las autoridades monetarias comenzaron a adoptar una serie de medidas en materia financiera, como por ejemplo, la liberalización de las tasas de interés; la eliminación del requerimiento de reserva obligatoria como 
instrumento para dirigir el crédito a sectores específicos; la supresión de los incentivos fiscales; el establecimiento de un encaje único para todos los instrumentos de la banca comercial y se inició un proceso de fusión de intermediarios financieros, como condición para optar por la figura de banca múltiple, modalidad institucional creada mediante resolución de la Junta Monetaria.

Debemos reconocer que el proceso de fusión forzada inducido por las autoridades monetarias tuvo un costo de importancia para aquellas instituciones financieras que hicieron una inversión para convertirse en multibanco, el cual no ha podido ser compensado por dichas instituciones en razón de que la reducción del encaje legal que se había establecido originalmente no se ha producido. De esa forma, las autoridades monetarias se libraron de un costo financiero significativo que tuvo que ser asumido tanto por las instituciones bancarias como por los propios deposit antes. Con el objeto de evitar la pérdida de los ahorros de los depositantes, las autoridades monetarias tuvieron que salir al rescate de las mismas mediante emisiones internas del Banco Central a través de pagos en efectivo y/o colocaciones de valores con tasas de rendimiento de mercado, todo lo cual contribuye a la expansión de los medios de pago, ya sea a corto o mediano plazo.

En la actualidad el sistema financiero se encuentra en una etapa de readecuación a las nuevas circunstancias, fundamentalmente, terminando con la especialización y segmentación del mercado y mejorando sustancialmente el marco regulatorio como el de supervisión bancaria y promoviendo la capitalización de la banca. Las circunstancias adversas que tuvo que enfrentar el sistema financiero en lo que concierne al exceso de regulación, han empezado a revertirse a partir de las medidas de liberalización financiera 
adoptadas por las autoridades monetarias.

Ahora bien, debe quedar claro que el proceso de liberalización del mercado financiero implica mayor grado de libertad para operar de acuerdo a las reglas del mercado, pero sin descuidar los niveles de solvencia y liquidez de los intermediarios financieros a fin de no comprometer los ahorros que les han sido confiados en calidad de depósitos.

La experiencia nos muestra que aquellos países que emprendieron procesos de apertura y liberalización sin adoptar adecuadas medidas preventivas como de supervisión entraron en crisis generalizadas de las instituciones financieras, con elevados costos fiscales, como ocurrió por ejemplo, en Chile, Argentina y Uruguay en la década de los años 80 .

El proceso de reforma financiera emprendido por las autoridades monetarias, se enmarca dentro del programa de reformas económicas iniciado a partir de 1990. Lamentablemente, dicho proceso se encuentra inconcluso, lo que crea serias interrogantes y preocupaciones entre los agentes productivos pues varias de las reformas aún no concluyen, otras se encuentran pendientes de aprobación Congresional y algunas están pendientes de diseño, aprobación y posterior puesta en marcha.

Es evidente el consenso que se tiene acerca de la necesidad de llevar a cabo la reforma financiera, no solamente por la constatación de que el sistema financiero no estaba en condiciones de satisfacer adecuadamente la movilización eficiente de los ahorros nacionales y asignarlos a las actividades productivas sino también por la ausencia de autonomía en las decisiones monetarias y de supervisión bancaria. 
La reforma financiera implica fortalecer la capacidad del sector financiero para movilizar y asignar recursos en la economía, lo que implica mayores niveles de competencia entre y dentro de los mercados financieros y la presencia de economías de escala en las operaciones de las instituciones. Lo anterior deberá traducirse en mayores niveles de eficiencia en cada uno de los intermediarios financieros que forman parte del sistema, pues éstos son parte esencial para que el ahorro nacional se convierta en inversión productiva.

Para asegurar la estabilidad y solvencia del sistema financiero se requiere fortalecer el entorno macroeconómico que lo rodea, mediante la adopción de políticas fiscales, monetarias, cambiarias y crediticias, estables y transparentes de lo contrario se producen presiones y distorsiones innecesarias, no solamente en el sector financiero, sino también sobre todos los entes económicos del país

El Código Monetario-Financiero constituye una de las reformas macroeconómicas de mayor relevancia e importancia en la legislación del pais, la cual ha sido concebida por un lado para adecuar la legislación a la realidad cotidiana $y$, por otro lado, para fortalecer institucionalmente los mecanismos de regulación y supervisión bancaria, para configurar patrones más rigurosos de solvencia y eficiencia, para mejorar el proceso de asignación de los recursos, así como para promover una mayor transparencia del sistema financiero con el objeto de asegurar los recursos de los depositantes.

Es oportuno señalar que el Proyecto de Código Monetario sólo abarca la parte monetaria y bancaria, dejando en consecuencia aspectos financieros de importancia que deberán ser incorporados posteriormente al mismo o en su defecto ser objeto de otras legislaciones. Tal es el caso de 
lo relativo al mercado de valores y de capitales, complemento fundamental del Código Monetario-Financiero, pues el mismo representa el eje central del financiamiento de largo plazo, es decir, del financiamiento para el desarrollo.

El mercado de capitales debe basarse en una de las fuentes más estables y significativas de financiamiento a largo plazo, los llamados fondos de pensiones, que tienen el potencial no sólo de promover el ahorro y la inversión, sino de constituirse en uno de los pilares de crecimiento sostenido de la economía dominicana, para lo cual se requiere de una reforma al sistema de seguridad social en el pais.

El Proyecto de Código Monetario-Financiero contiene en una sola legislación todas las disposiciones en materia de regulación monetaria, crediticia y cambiaria así como lo concerniente a las funciones que le corresponden al Banco Central como a la Superintendencia de Bancos. Se pretende que tanto los organismos responsables de trazar la política monetaria como aquellos de supervisión y las propias instituciones financieras puedan tener una mayor capacidad de respuesta a las cambiantes condiciones del mercado. Sería, sin embargo, prudente que la parte relativa a la autonomía del Banco Central sea aún más fortalecida en el Proyecto de Código Monetario, como también contemplar la posibilidad de eliminar cualquier posibilidad de financiamiento al sector público consolidado, a fin de evitar presiones innecesarias sobre los agregados monetarios. De la misma manera, es altamente saludable que los miembros del sector privado que formen parte de la Junta Monetaria lo sean a tiempo completo y dedicación exclusiva, a fin de evitar posibles conflictos de interés que pueden surgir cuando se asiste de manera esporádica al organismo responsable de trazar la política monetaria del 
país.

La otra parte fundamental del Proyecto de Código Monetario-Financiero es la relativa a las disposiciones de regulación financiera en cuanto se refiere a la apertura y funcionamiento de las entidades financieras así como el conjunto de Normas Prudenciales que rigen el comportamiento de dichas instituciones.

Dichas Normas Prudenciales establecen límites y prohibiciones respecto a las operaciones activas y pasivas que puedan realizar las instituciones financieras y disponen además nuevas y más estrictas definiciones sobre el concepto de capital y reservas de las instituciones, a fin de prevenir problemas de solvencia y minimizar la concentración de riesgos.

Si bien el Proyecto de Código Monetario-Financiero aún se encuentra pendiente de sanción Congresional, todas las regulaciones financieras contenidas en dicho Proyecto se encuentran en la actualidad en plena vigencia mediante Resoluciones de la Junta Monetaria del Banco Central. Sólo la parte relativa al Banco Central, a la Superintendencia de Bancos y sobre la Ley Monetaria no han podido ser puestas en ejecución de manera administrativa, por lo cual es recomendable que a la mayor brevedad se pueda contar con la aprobación final del Código ya que es uno de los instrumentos de regulación de mayor importancia para el buen desenvolvimiento de las actividades productivas.

El proceso de reforma financiera iniciado administrativamente por las autoridades monetarias se basa fundamentalmente en tres disposiciones de la Junta Monetaria:

a) las Normas Prudenciales del 11 de diciembre de 1992, 
b) la creación de la Banca de Servicios Múltiples y en

c) las Normas Bancarias sobre Clasificación de Activos del 29 de junio de 1993.

Las Normas Prudenciales establecen requerimientos más estrictos en materia de solvencia, es decir, una relación más depurada entre el capital y reservas de las instituciones y sus activos y operaciones contingentes; limitan el monto de los activos fijos que pueden poseer los intermediarios financieros; imponen restricciones a los límites de préstamos que pueden ser otorgados a una misma persona física o jurídica y establecen limitaciones al otorgamiento de préstamos a partes vinculadas.

Asimismo, las Normas Prudenciales establecen regulaciones a las inversiones que pueden ser realizadas por las instituciones financieras tanto en empresas de naturaleza financiera que no capten recursos del público como en otros tipos de empresas no financieras. Tales disposiciones administrativas se consolidarán por la vía legislativa, una vez que el Congreso Nacional apruebe el Proyecto de Código Monetario-Financiero.

Lo que se pretende es que todas las instituciones financieras, no importa su tamaño, sean sometidas a un marco de regulación económica y prudencial uniforme, que les permita competir en igual condiciones con instituciones, tanto internamente, como con las de otros países, a la luz del proceso de globalización de las economías.

Por otra parte, uno de los objetivos básicos de la Reforma Financiera es el de establecer una estructura en la que haya en su etapa inicial, menos instituciones y que éstas sean más sólidas y eficientes. El Proyecto de Código Monetario-Financiero prevé básicamente la existencia de 
cuatro tipos de instituciones:

a) Bancos de Servicios Múltiples

b) Bancos de Ahorros y Crédito

c) Corporaciones de Crédito

d) Asociaciones de Ahorros y Créditos

Cada una de esas modalidades institucionales se diferencian fundamentalmente en cuanto se refiere al monto del capital y reservas que se requiere en cada caso así como en cuanto al tipo de operaciones que éstas puedan efectuar.

Las Normas Bancarias sobre Clasificación de Activos establecen la forma y los criterios sobre la evaluación de la calidad y los riesgos de los activos de las instituciones financieras, es decir, la cartera de préstamos, las inversiones financieras y los activos recibidos en dación de pago.

De acuerdo a la categoría en que sean clasificados dichos activos se deben establecer provisiones de riesgos sobre cada una de dichascategorías. Es importante señalar que la cartera de préstamos de los intermediarios fin ancieros comprende los préstamos comerciales, los préstamos para el consumo y los préstamos hipotecarios para la vivienda.

Gracias a la aplicación de estas Normas, las autoridades monetarias y de supervisión bancaria tienen en la actualidad un mayor grado de conocimiento de la calidad de los activos de nuestras instituciones financieras, por lo que sería recomendable que se proceda a reducir y posteriormente a eliminar el encaje legal y que el mismo sea sustituido por las llamadas operaciones de mercado abierto, como instrumento regulador de la masa monetaria, tal y como se contempla en el Proyecto de Código Monetario-Financiero. En un sistema financiero en el que no se aplican controles sobre las tasas de interés o la asignación del crédito, las operaciones de 
mercado abierto son los principales instrumentos de la política monetaria y crediticia.

Es importante señalar que las reservas que se crean por concepto de la aplicación de las Normas Bancaria no son consideradas como un gasto para fines de la determinación de la renta neta imponible con lo cual se afecta no solamente los resultados de las instituciones sino también el capital de las mismas y eventualmente el índice de solvencia. En adición a lo anterior, debemos mencionar que al estar las instituciones financieras en la obligación de llevar sus operaciones contables bajo el método de lo percibido no pueden considerar los intereses por cobrar como parte de sus ingresos, con lo cual se afecta la rentabilidad de las mismas y constituye en consecuencia una especie de encaje adicional. Sin embargo, cualquier cambio en el régimen de los ingresos tiene que ser muy bien fiscalizado a fin de impedir el registro de fuentes de ingresos provenientes de intereses derivados de activos de dudosa recuperación.

Es evidente que todo lo anterior, unido a la Ley de Patentes que se aplica a los intermediarios financieros, así como el grado de in eficiencia que aún predomina en ciertas instituciones tienden a encarecer el costo del dinero, afectando de esa forma los niveles de inversión productiva como de concentración del crédito.

Una mayor eficiencia de los intermediarios financieros tiene como consecuencia aumentar la posibilidad de canalizar recursos a los sectores reales de la economía a tasas competitivas, lo que supone una reducción de los márgenes de intermedicación, aunque debe quedar claro que la disminución del "spread" o margen no puede hacerse únicamente con cargo a la rentabilidad bancaria. Es necesario reducir los costos fijos de la intermediación financiera. 
La condición básica para lograr el éxito de la Reforma Financiera consiste en mantener la estabilidad macroeconómica reconociendo, asimismo, que todo esfuerzo de reestructuración financiera debe ser considerado como un elemento importante en todo programa de estabilización macroeconómica. El sector financiero no debe ser utilizado para financiar déficits fiscales o para ser fuente deimpuestos que gravan sus operaciones de manera específica, ni tampoco el sector público puede introducir presiones indebidas sobre la estabilidad y el valor de los activos financieros derivadas de políticas fiscales y monetarias expansivas.

Los principales beneficios del programa de reforma del sector financiero de la República Dominicana serían el de contar con una estructura de intermediación más eficiente así como la introducción de salvaguardias adecuadas para garantizar la estabilidad y solvencia de todos los intermediarios financieros.

De esa forma se podrían movilizar ahorros en la economía, lo cual tendría efectos positivos en los niveles y calidad de la inversión privada. Por otra parte, las disposiciones de regulación, disciplina, control y supervisión que se contemplan, garantizarían la seguridad del sistema financiero, lo que contribuiría a reducir al mínimo el riesgo de quiebra de algunos intermediarios, así como los consiguientes costos económicos y sociales que normalmente se generan cuando se producen tales situaciones.

Resulta muy difícil, por ejemplo, evaluar acertadamente los efectos sociales de la Reforma Financiera, sobre todo en la población de menores ingresos, sin embargo, en la medida en que se disponga de un sistema financiero estable, la reforma financiera debería encauzar más eficientemente los recursos financieros hacia actividades productivas del sector 
privado y en consecuencia a generar más empleo y un nivel más elevado de ingresos, protegiendo además el ahorro que se encuentra depositado en el sistema.

Recordemos que una Reforma Financiera no constituye un objetivo en si misma, sino un medio para que los mercados financieros y de capital puedan brindar mejores servicios a la comunidad, es decir, movilizar más recursos, mejorar la intermediación y ampliar sus alcances, diversificándose a más áreas geográficas, económicas y sociales.

La vigencia plena de la reforma financiera debe conducir a la prestación eficiente de los servicios financieros y, por ende, contribuir al desarrollo económico y social del país, siempre y cuando se logre lo siguiente:

a) que un amplio segmento de la población tenga acceso a una gama extensa de servicios financieros.

b) que dichos servicios sean prestados con eficiencia, lo cual es determinado por la magnitud y dispersión de los costos de transacción en que incurran todos los participantes en los mercados financieros.

c) que los servicios financieros ofrecidos sean de calidad, en términos de su flexibilidad, oportunidad y transparencia, $\mathrm{y}$,

d) que el volumen de recursos que se intermedie se realice a través de las reglas del mercado.

En otras palabras, la prestación eficiente de servicios financieros tiene un impacto positivo importante sobre la productividad de los recursos disponibles en la economía; sobre la tasa de crecimiento económico, a través de su impacto sobre los procesos de ahorro e inversión; sobre la 
estabilidad macroeconómica y la eficiencia en el manejo del riesgo; así como sobre la distribución del ingreso y la riqueza, al poner al alcance de quienes cuentan con pocos recursos propios, poder de compra adicional para que puedan aprovechar sus oportunidades productivas.

La reconquista de la estabilidad del sistema financiero crea expectativas positivas del público con respecto a la estabilidad del valor de los activos financieros, condición tan necesaria para la movilización de ahorros.

Siendo la República Dominicana un país con nivel muy bajo de ahorro interno, el sistema financiero, a la luz del Programa de Reforma, podría estimular la propensión al ahorro siempre y cuando las instituciones financieras compitan en igualdad de condiciones y se eviten procesos de desintermediación. Por otra parte, como las instituciones financieras tienen ahora que mostrar mayor nivel de transparencia frente al público, pues éstas tienen que publicar cada vez mayor número de información, tanto los ahorristas como los inversionistas podrán conocer con mayor grado de precisión la situación real de cada uno de los intermediarios financieros para fines de sus operaciones.

Es oportuno destacar que la transparencia de las instituciones financieras depende, en gran medida de la calidad de las informaciones, tanto crediticias como legales, que los usuarios de los recursos suministren a cada uno de los intermediarios financieros. La transparencia es un proceso que comprenden a los usuarios de los recursos, a los intermediarios financieros así como a los organismos responsables de trazar la política monetaria como a aquellos de la supervisión bancaria.

En ese proceso de transparencia se han logrado avances 
significativos, sin embargo todavía es mucho lo que falta por obtener de parte de los usuarios, pues algunos tienen la suspicacia de que dicha información podría ser utilizada por los organismos responsables de la administración tributaria. De ahí, la importancia que tiene la adopción de una amnistía fiscal, la cual vendría no solamente a ampliar la base de los contribuyentes, sino también a mejorar sustancialmente la calidad de las informaciones financieras que serían puestas a disposición de las instituciones del sistema financiero.

La reforma financiera es una parte importantísima del programa de reformas económicas, ya que un funcionamiento inadecuado del sector financiero conlleva a consecuencias negativas para el buen funcionamiento del sistema económico, lo que podría traducirse en la existencia de procesos inflacionarios, en desplazamiento del sector privado del acceso al crédito, en una asignación inadecuada de los recursos distributivos regresivos y se crearían, además, dificultades adicionales en el proceso de formación de ahorro.

Finalmente, debemos reconocer que toda reforma tiene costo y beneficio que se derivan de su puesta en vigencia y quizás la forma más valiosa de apreciar y medir el éxito de la reforma financiera consistiría en evaluar y comparar los resultados de la misma comparados con lo que hubiese ocurrido en ausencia de la reforma financiera. Como bien lo señala Adolfo C. Diz, la forma correcta de evaluar los resultados de una reforma financiera debe hacerse de manera similar a la que se efectúa en materia de evaluación de proyectos, donde la comparación válida no es la de antes y después, sino con el proyecto y sin el proyecto. 